\title{
Influence of the Solvent Nature on the Structure of Two-dimensional Nanoaggregates in Langmuir Layers of Copper Tetra-tert-butyltetrabenzotriazaporphyrin
}

\author{
Larisa A. Valkova, ${ }^{\text {a@ }}$ Alexander S. Glibin, ${ }^{a}$ and Oscar I. Koifman ${ }^{\mathrm{a}, \mathrm{b}}$ \\ ${ }^{a}$ Research Institute of Macroheterocyclic Compounds, Ivanovo State University of Chemistry and Technology, 153000 \\ Ivanovo, Russia \\ ${ }^{\mathrm{b}}$ Institute of Solution Chemistry of RAS, 153045 Ivanovo, Russia \\ @Corresponding author E-mail:valkova@isuct.ru
}

\begin{abstract}
The structure of nanostructured Langmuir layers of copper tetra-tert-butyltetrabenzotriazaporphyrin (CuTht $\left.{ }^{t} u_{\downarrow}\right)$ prepared using the solution in methylene chloride at different degrees of initial surface coverage (cedge from 10 to $51 \%)$ is determined. The significant change of the monolayer structure due to changes in initial conditions is shown. A comparative analysis of the quantitative structure parameters and properties of floating layers of CuThp'Bu prepared using solutions in benzene and methylene chloride is performed. It is shown that in the case of the aromatic solvent (benzene, cedge $=10 \%$ ) and the azaporphyrin with the disturbed $\pi$-system (CuThpt $B u$ ) intermolecular interactions APwater became prevailing, what leads to formation of dense and rigid monolayers with the most open (face-on) structure of nanoaggregates.
\end{abstract}

Keywords: Two-dimensional nanoaggregates, Langmuir layers, quantitative analysis of isotherms, copper tetra-tertbutyltetrabenzotriazaporphyrin.

\section{Introduction}

Self-assembly of porphyrins is one of prevailing concepts in development of functional porphyrin systems, some of which reveal exceptional properties similar to that of systems found in nature. ${ }^{[1-6]}$ Molecular-level 2D control of organic compounds is a rapidly developing part of nanotechnology. Controlled self-assembly of porphyrins may be embodied using the Langmuir-Blodgett (LB) method, which allows one to build highly ordered layered molecular ensembles both on liquid-gas interface and on solid substrates..$^{[7-10]}$

Properties of thin-film organic nanomaterials are defined by their structure, which in the case of LB technique depends on the structure of floating layers. By changing the structure of the layer, which will be transferred onto a solid substrate, one can drastically change the structure of films being prepared. Porphyrazine nanoparticles in LB films were formed for the first time just owing to adequately chosen structure of the layers meant for the transfer ${ }^{[1]]}$ This makes the study of structure and properties of azaporphyrin Langmuir layers unavoidable step in the solution of the problem of fabrication of nanomaterials based on these compounds.

The solvent used to dissolve a compound under study in order to prepare a solution, which will be applied to water surface is one of the factors influencing formation of nanostructures in floating layers. Usually a volatile solvent, immiscible with water, is used. It is believed that the solvent evaporates from the surface in 10-15 minutes. At the same time, macroheterocycles may form solvates. ${ }^{[12-15]}$ An increase of electron density in the macrocycle of a ligand (due to electron effects of substituents and/ or metal-ligand $\pi$-bonds) promotes formation of stable $\pi$ - $\pi$-complexes with $\pi$-acceptors whose ligand plays a role of a $\pi$-electron density donor (and vice versa). ${ }^{[16]}$ Specifically, CuL has high energy of interaction with benzene. $\mathrm{CuL} \cdot 2 \mathrm{C}_{6} \mathrm{H}_{6}$ species are the most energetically stable ones among solvates of metalloporphyrins. For $\mathrm{CuL} \cdot 2 \mathrm{C}_{6} \mathrm{H}_{6}$ and $\mathrm{CuL} \cdot \mathrm{C}_{6} \mathrm{H}_{6}$, for example, the enthalpy of benzene evaporation from crystallosolvates is 27.4 and $46.6 \mathrm{~J} / \mathrm{mol}$, the temperature of the onset of desintegration of crystallosolvates is 60 and 85 degrees centigrade, respectively. Earlier association of tetra-tertbutylsubstituted copper phthalocyanine $\left(\mathrm{CuThp}^{t} \mathrm{Bu}_{4}\right)$ with cyclohexene, hexene, benzene, pyridine was studied. ${ }^{[15]}$ With the use of GLC method the association constants of $\mathrm{CuThp}{ }^{t} \mathrm{Bu}_{4}$ with said molecules were measured.

Thus, the compound studied in this work can form complexes with solvents. The stability of the complexes is determined not only by the structure of the molecule, but also by a nature of the solvent. This allows one to expect that a solvent used to form floating layers will influence the structure of copper tetrabenzotriazaporphyrin floating layer due to solvatation effects.

Floating layers of metal-free tetra-tertbutyltetrabenzotriazaporphyrin were studied ${ }^{[17]}$ the data of comparative analysis of Langmuir layer of its copper complex and tetra-tert-butylsubstituted copper phthalocyanine were also presented by us, ${ }^{[18]}$ although the structure of floating layers was estimated only qualitatively with the use of conventional method of analysis of compression isotherms of a layer. 
Advantages of the method of quantitative analysis ${ }^{[4,19]}$ which is currently being developed, as has been shown by us by the example of investigation of $\mathrm{CuThp}^{t} \mathrm{Bu}_{4},{ }^{[4]}$ come from its ability to determine ranges of existence of single-phase layer states and quantitative parameters of floating layers (the size of nanoaggregates formed in layers, the number of molecules in a nanoaggregate, compressibility, and the pressure range where the given state exists). Further, it has been shown (including the use of Brewster angle microscopy) that within the $110-700 \mathrm{nmol} / \mathrm{m}^{2}$ range of initial surface concentration, corresponding to initial degree of surface coverage $c_{\text {edge }}=6-40 \%$ (the most common in Langmuir-Blodgett technique) the layer structure determined by the quantitative method and by the conventional one may differ drastically.

The main goal of the present work is to compare quantitatively the structure and properties of floating layers of tetra-tert-butylsubstituted copper tetrabenzotriazaporphyrin formed using solutions in benzene and methylene chloride.

\section{Experimental}

The compound under study was synthesized by N.Yu. Borovkov from 4-tetrabutylphthalonitrile ${ }^{[20,21]}$ and chromatographically purified on alumina using benzene as an eluent. Its structure was confirmed by NMR, IR and UV-vis spectra. $\pi$ - $A$ isotherms were obtained with the use of the Langmuir trough made by Joyce-Loebel (England). Solutions of $\mathrm{CuThp}^{t} \mathrm{Bu}_{4}$ in benzene and methylene chloride $(C=625 \mu \mathrm{mol} / \mathrm{l})$ were used to form floating layers. Layer compression with the speed of $4.8 \mathrm{~cm}^{2} /$ min was started 15 minutes after the application. Surface pressure was measured using a Wilhelmy balance with $0.02 \mathrm{mN} / \mathrm{m}$ accuracy, while the accuracy for the measurement of the $A$ value was $2 \%$.

Geometric parameters of the molecule - projection area $A_{\text {proj(face) }}=2.2 \mathrm{~nm}^{2}, A_{\text {proj(edge) }}=0.7 \mathrm{~nm}^{2}$, areas of circumscribed rectangles $2.9 \mathrm{~nm}^{2}$ and $1.2 \mathrm{~nm}^{2}$ respectively (Figure 1a) and in densely packed monolayer on water surface $\left(A_{\text {modface })}=2.7 \mathrm{~nm}^{2}\right.$ and $A_{\text {mod(edge) }}=0.9 \mathrm{~nm}^{2}$ ) were determined from corresponding molecular models built in HyperChem 7.01 software (using the MM+ calculation procedure).

Structure analysis of floating layers was done with the method of quantitative analysis of compression isotherms, based on the Volmer equation, ${ }^{[22]}$ generalized to the case when structural units of 2D-gas are molecular aggregates rather than individual molecules. ${ }^{[23-25,4]}$ A single-phase state of a layer is described by the following equation: $\pi\left(A-A_{m o l}\right)=n^{-1} k T$, where $A_{m o l}$ is the surface area per one molecule in a structure unit of a layer (a $2 \mathrm{D}$ nanoaggregate); $k$ is the Boltzmann constant; $\mathrm{T}$ is absolute temperature; $n$ is the number of molecules in a nanoaggregate (an aggregation number). Isotherms plotted in $\pi A-\pi$ coordinates comprise linear and nonlinear parts. The former corresponds to single-phase states, and the tangent of the slope angle of the linear part is equal to $A_{m o l}$ The ratio of $k \mathrm{~T}$ to the initial ordinate of the intersection of the axis and a straight line, whose segment approximates the linear part, is equal to $\mathrm{n}$. The $\mathrm{n}$ value corresponds to the peak of distribution of number of molecules in nanoaggregates. Diameter $D_{a g g r}$ of an 2D nanoaggregate, which, according to the employed model (Figure 1b), has a circular shape, is determined from its area $S_{a g g r}=A_{m o l} n$. Distance $d$ between boundaries of aggregates (interaggregate spacing) is calculated under the assumption that the aggregates are, on average, located at equal distances from each other $\left(d=\sqrt{4 \cdot A_{i} \cdot n / \pi}-\sqrt{4 \cdot A_{m o l} \cdot n / \pi}\right)$, where $A_{i}$ is the abscissa of the beginning of a stable part of a $\pi$ - $A$ isotherm. Within a linear part of a $\pi A-\pi$ plot the tilt angle $\psi$ of molecules in a stack of compact water free aggregate was calculated from the $A_{\text {mol }}=A_{\text {edge }} / \sin \psi$ relationship. A degree of water surface coverage by nanoaggregates at an onset point of a stable state was calculated as $c_{\text {aggr }}=S_{\text {aggr }} / A_{i}$ and a degree of face-on nanoaggregates surface coverage was calculated as $c_{\text {aggr }}=A_{\text {proj(face) }} / A_{\text {mol }}$. Water content in an aggregate and free water content in a layer per one molecule at an onset point of a stable state were calculated as $w_{i n}=A_{m o l}-A_{p r o j}$ and $w_{\text {free- } i}=A_{i}-A_{\text {mol }}$, respectively. Layer compressibility within a selected part of the isotherm corresponding to the stable state of the layer was calculated as $B=A_{i}-A_{f} /\left(\pi_{f}-\pi_{i}\right) A_{i}$, where $\pi_{i}$ and $\pi_{f}-$ pressures at initial and final points of a stable layer state.

Values of area per molecule and number of molecules in a nanoaggregate $A_{\text {mol }}$ and $n$ were determined using linear least-square approximation of a part of the $\pi A-\pi$ plot with the maximum $\pi A$ error not exceeding 3\%. The other maximum errors are $3 \%$ for $A_{\text {mol }}, \Delta \pi$ and $c_{i-a g g r} ; 5 \%$ for $c_{\text {face }}$ and $\psi ; 7 \%$ for $D$ and $w_{\text {free- } i} ; 8 \%$ for $B ; 10 \%$ for $w_{i n}, n$ and $d_{i}$.

\section{Results and Discussion}

The analysis of $\pi-A$ isotherms and $\pi A-\pi$ plots of $\mathrm{CuThp}{ }^{t} \mathrm{Bu}_{4}$ floating layers prepared using solutions in methylene chlo ride at the initial degree of surface coverage values of $c_{\text {edge }}\left(c_{\text {face }}\right)=10(30), 33$ and $51 \%$ (Figure 2 ) shows significant changes in the monolayer structure: the least tilt angle of molecules in a nanoaggregate's stacks changes from a

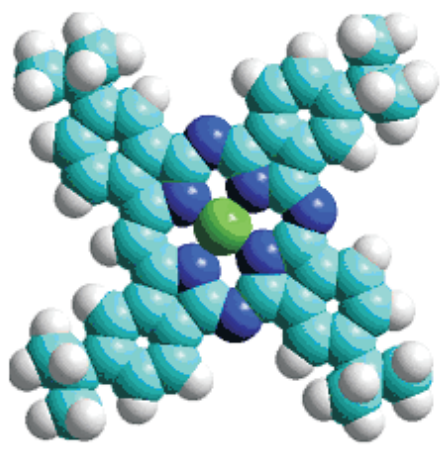

$\mathrm{S}_{\text {face }}=2.9 \mathrm{~nm}^{2}$

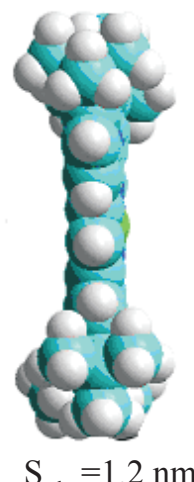

$\mathrm{S}_{\text {edge }}=1.2 \mathrm{~nm}^{2}$ b

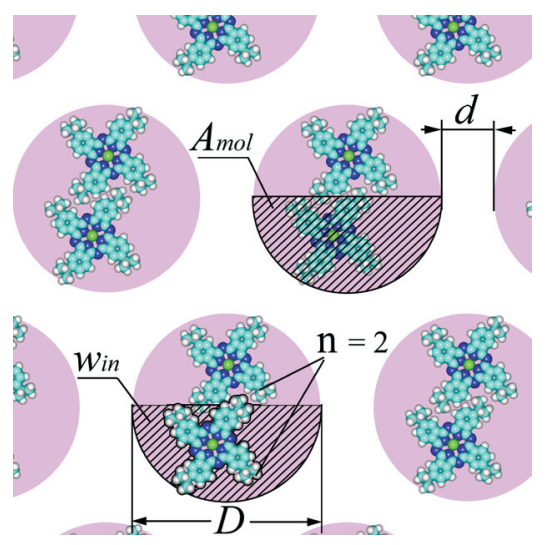

Figure 1. Molecular dimensions of copper tetra-tert-butyltetrabenzotriazaporphyrin (a) and schematic representation of a monolayer model (b). 
$\psi=20^{\circ}$ ( $\tau$-type) to $\psi=76^{\circ}$ ( $\alpha^{\prime}$-type). Quantitative parameters of the structure and properties of stable monolayer state are presented in Table 1.

The characteristic feature of monolayers prepared using the solution in methylene chloride is the permanency of the aggregation number $(n=45)$ in the wide range of initial surface concentration $\left(c_{\text {edge }}=10-51 \%\right)$. The compressibility of monolayers decreases as $c_{\text {edge }}$ grows. Monolayers with the "open" nanoaggregates $\left(\psi=20^{\circ}\right.$, $\tau$-type) which are interesting for practical applications may be formed at $c_{\text {edge }}=10 \%$ within the surface pressure range of $0-1.7 \mathrm{mN} / \mathrm{m}$. Such a monolayer features low density (the separation between aggregates is $d_{i}=1.7 \mathrm{~nm}$, the degree of surface coverage by nanoaggregates is $c_{i-a g g r}=77 \%$ ) and high compressibility $(B=140 \mathrm{~m} / \mathrm{N})$. A Langmuir layer with two-dimensional aggregates of "closed" structure ( $\alpha$ '-type) prepared at $c_{\text {edge }}=51 \%$ has the widest stability range with respect to the surface pressure $(\Delta \pi=3.5 \mathrm{mN} / \mathrm{m})$.

Figure 3 shows how the nature of a solvent influences the structure of a layer by presenting $\pi$ - $A$ isotherms of layers prepared using solutions in benzene and methylene chloride with equal amount of the substance applied to the water surface $\left(c_{\text {edge }}=10 \%, N_{0}=227 \mathrm{nmol} / \mathrm{m}^{2}\right)$.

In layers prepared using benzene as a solvent at $c_{\text {edge }}=10 \%$ in the low pressure region $(\pi<2.0 \mathrm{mN} / \mathrm{m})$ face-on monolayers where molecules are flat with the water surface

Table 1. Parameters of floating layers of $\mathrm{CuThp}^{t} \mathrm{Bu}_{4}$ formed from solutions in benzene and methylene chloride.

\begin{tabular}{|c|c|c|c|c|c|c|c|c|c|c|c|}
\hline $\begin{array}{l}N_{0}, \mathrm{nmol} / \mathrm{m}^{2} \\
\left(c_{\text {face }}, c_{\text {edge }}\right), \%\end{array}$ & $\begin{array}{c}\text { Layer state } \\
\text { (monolayer } \\
\text { type) }\end{array}$ & $\begin{array}{c}c_{i \text {-face }}-c_{\text {f-face }} \\
\left(c_{i-\text { edge }}-c_{\text {f-edge }}\right), \\
\left(\left(c_{i \text {-agg }}\right)\right), \%\end{array}$ & $\begin{array}{c}\pi_{\mathrm{i}}-\pi_{\mathrm{f}}(\Delta \pi) \\
\mathrm{mN} / \mathrm{m}\end{array}$ & $\begin{array}{l}A_{\text {mol }}, \\
\mathrm{nm}^{2}\end{array}$ & $n$ & $\begin{array}{c}D_{a g g r}, \\
\mathrm{~nm}\end{array}$ & $\psi,^{\mathbf{o} \Delta}$ & $\begin{array}{l}w_{\text {in }} / A_{m o l}, \\
\left(c_{\text {aggr }}\right), \%\end{array}$ & $\begin{array}{l}w_{\text {free }-i}, \\
\mathrm{~nm}^{2}\end{array}$ & $\begin{array}{c}d_{i}, \mathrm{~nm} \\
\left(d_{i} / D_{a g g r}\right)\end{array}$ & $B, \mathrm{~m} / \mathrm{N}$ \\
\hline \multicolumn{12}{|c|}{ Solvent: methylene chloride } \\
\hline $\begin{array}{c}227 \\
(30,10)\end{array}$ & $\begin{array}{l}\text { Mono edge } \\
\text { ( } \tau \text {-type })\end{array}$ & $\begin{array}{c}66-87 \\
(22-29) \\
((77))\end{array}$ & $\begin{array}{l}0-1.7 \\
(1.7)\end{array}$ & 2.6 & 46 & 12 & 20 & $71^{*}$ & 0.8 & $\begin{array}{c}1.7 \\
(0.14)\end{array}$ & 140 \\
\hline $\begin{array}{c}758 \\
(100,33)\end{array}$ & $\begin{array}{l}\text { Mono edge } \\
\text { ( } \alpha \text {-type) }\end{array}$ & $\begin{array}{c}175-217 \\
(58-72) \\
((79))\end{array}$ & $\begin{array}{c}0.3-1.9 \\
(1.6)\end{array}$ & 1.0 & 44 & 7.4 & 65 & $26^{*}$ & 0.3 & $\begin{array}{c}0.9 \\
(0.1)\end{array}$ & 120 \\
\hline $\begin{array}{c}1150 \\
(154,51)\end{array}$ & $\begin{array}{l}\text { Mono edge } \\
\text { ( } \alpha^{\prime} \text {-type) }\end{array}$ & $\begin{array}{c}196-240 \\
(65-80) \\
((83))\end{array}$ & $\begin{array}{c}0.3-3.8 \\
(3.5)\end{array}$ & 0.9 & 46 & 7.3 & 76 & $21^{*}$ & 0.2 & $\begin{array}{c}0.7 \\
(0.1)\end{array}$ & 52 \\
\hline \multicolumn{12}{|c|}{ Solvent: benzene } \\
\hline $\begin{array}{c}227 \\
(30,10)\end{array}$ & Mono face & $\begin{array}{l}67-77 \\
(22-26) \\
((87))\end{array}$ & $\begin{array}{c}0.1-2.0 \\
(1.9)\end{array}$ & 2.9 & 46 & 13 & 0 & $\begin{array}{c}23 \\
(76)\end{array}$ & 0.4 & $\begin{array}{c}0.9 \\
(0.07)\end{array}$ & 71 \\
\hline
\end{tabular}

*amount of water in aggregates is calculated in assumption of vertical orientation of molecules.

${ }^{\Delta}$ for edge-on aggregates the least tilt angle of molecules in stacks is presented.

$N_{0}$ - the initial surface concentration; $c_{\text {face }}, \%$ - the face-on initial degree of surface coverage; $c_{\text {edge }}, \%$ - the edge-on initial degree of surface coverage; $c_{\text {ifface }}\left(c_{\text {i-edge }}\right)$ and $c_{f-\text { face }}\left(c_{\text {f-edge }}\right)$ - the degrees of surface coverage at the onset point of a stable state, $c_{i-\text { aggr }}$ - the degree of coverage of water surface by aggregates at the onset point of a stable state; $A_{m o l}$ - the area per molecule in a nanoaggregate; $\pi_{\mathrm{i}}-\pi_{\mathrm{f}},(\Delta \pi)$ - the pressure interval of existence of a stable state; $n$ the aggregation number; $D_{a g g r}$ - the diameter of a nanoaggregate; $\psi$ - the tilt angle of molecules; $w_{i n}$ and $w_{\text {free- } i}$ - water content in an aggregate and free water content in a layer (per one molecule) at the onset point of a stable state; $c_{a g g r}-$ the degree of surface coverage of nanoaggregates; $d_{i}$ - the distance between boundaries of nanoaggregates at initial point of stable state; $B$ - the monolayer compressibility.

a

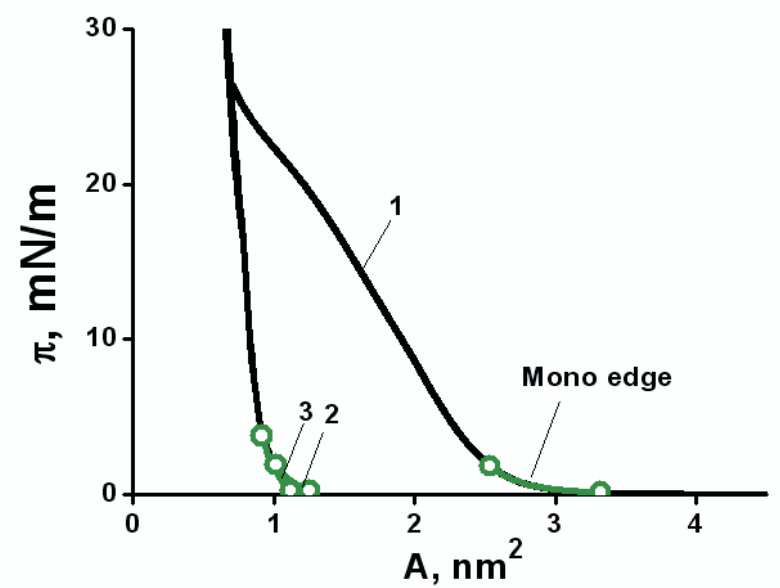

b

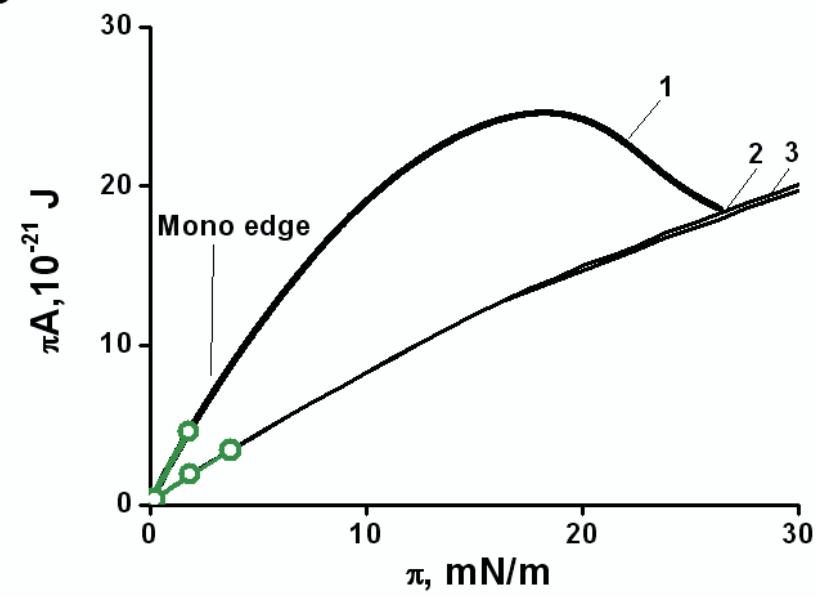

Figure 2. $\pi$-A isotherms (a) and $\pi A$ - $\pi$ plots (b) for $\mathrm{CuThp}^{t} \mathrm{Bu}_{4}, C=625 \mu \mathrm{mol} / 1$ (methylene chloride), $c_{\text {edge }}=10$ (1), 33 (2), $51 \%$ (3). The dots denote boundaries of stable monolayer states of the layer. 
a

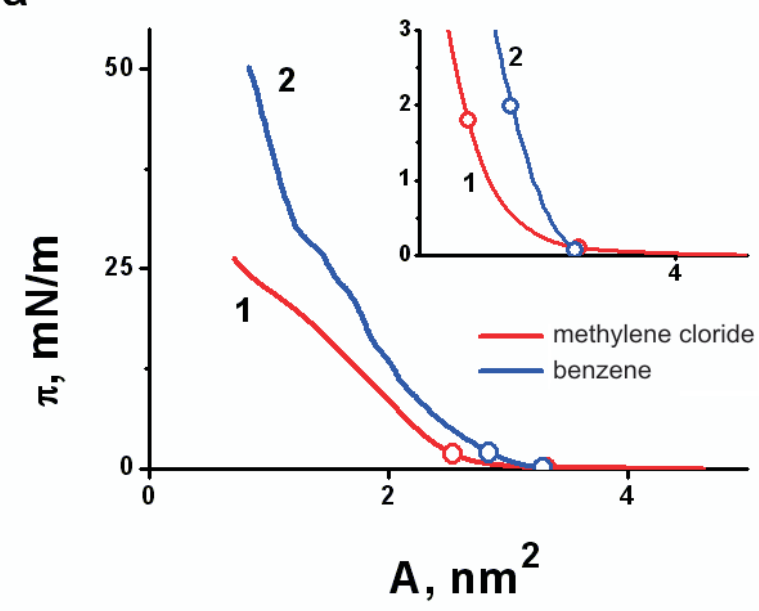

b

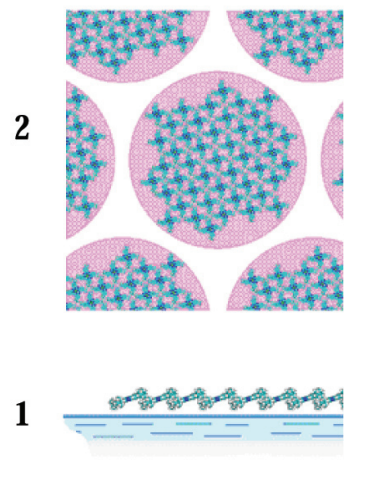

Figure 3. $\pi-A$ isotherms (a) and a schematic structure (b, $1-x z$ projection of a nanoaggregate, the edge-on structure; 2 - fragment of xy projection $\left(21 \times 21 \mathrm{~nm}\right.$, the face-on structure of a layer) of $\mathrm{CuThp}^{t} \mathrm{Bu}_{4}$ floating layers prepared at $c_{\text {edge }}=10 \%$ using solutions in methylene chloride (1) and benzene (2). The dots denote the boundaries of regions corresponding to stable monolayer states of the layers. The inset to Figure 3a shows the low pressure zone in more detail.

$(\psi=0$, plot and packing 2 in Figure 3$)$ are formed, whereas the methylene chloride solution under similar conditions produces $\tau$-type edge-on monolayers (plot and packing 1 in Figure 3). Monolayers exist within similar ranges of current surface concentration $c_{i \text {-face }}-c_{\text {fface }}\left(c_{i \text {-edge }}-c_{\text {f-edge }}\right), \quad 67-77 \%$ $(22-26 \%)$ and $66-87 \%(22-29 \%)$, respectively. Properties of the monolayers differ significantly: the compressibility, the interaggregate spacing and the amount of free water for the monolayer prepared using benzene is two times less (Table 1). The number of molecules in aggregates does not depend on the initial degree of surface coverage and on the solvent.

\section{Conclusion}

The structure of nanostructured Langmuir layers of coppertetra-tert-butyltetrabenzotriazaporphyrin $\left(\mathrm{CuThp}{ }^{t} \mathrm{Bu}_{4}\right)$ prepared using the solution in methylene chloride at different values of initial surface coverage $\left(c_{\text {edge }}\right.$ from 10 to $51 \%$ ) is determined. The significant change of the monolayer structure due to the changes in initial conditions is shown: the least tilt angle of molecules in nanoaggregate's stacks is from $\psi=20^{\circ}$ ( $\tau$-type) to $\psi=76^{\circ}$ ( $\alpha^{\prime}$-type). A Langmuir layer with two-dimensional aggregates of "closed" structure $(\alpha$ 'type) prepared at $c_{\text {edge }}=51 \%$ has the widest stability range with respect to the surface pressure $(\Delta \pi=3.5 \mathrm{mN} / \mathrm{m})$.

A comparative analysis of the quantitative structure parameters and properties of floating layers of copper tetratert-butylsubstituted tetrabenzotriazaporphyrin prepared using solutions in benzene and methylene chloride is carried out. It is shown that in the case of the aromatic solvent (benzene, $c_{\text {edge }}=10 \%$ ) and the azaporphyrin with the disturbed $\pi$-system $\left(\mathrm{CuThp}^{t} \mathrm{Bu}_{4}\right)$ intermolecular interactions AP-water became prevailing, what leads to formation of dense and rigid monolayers with the most open (face-on) structure of nanoaggregates. On the other hand, monolayers prepared using methylene chloride consist of two-dimensional nanoaggregates with lateral arrangement of molecules in stacks. Unlike tetra-tert-butylsubstituted copper phtalocyanine studied earlier, ${ }^{[4]}$ the number $(n=45)$ of molecules in nanoaggregates does not depend on both the initial degree of surface coverage and the solvent.

Acknowledgements. This work was supported by the "Researchers and Professors of Innovative Russia 2009 2013" Federal targeted program, Lot 3, 1.2.2 «Nanotechnology and nanomaterials» (GK №14.740.11.0268).

\section{References}

1. Satake A., Kobuke Y. Tetrahedron 2005, 61, 13-41.

2. Ariga K., Nakanishi T., Michinobu T. J. Nanosci. Nanotechnol. 2006, 6, 2278-2301.

3. Ariga K., Nakanishi T., Hill J.P. Curr. Opin. Colloid Interface Sci. 2007, 12, 106-120.

4. Valkova L., Zyablov S., Erokhin V., Koifman O. J. Porphyrins Phthalocyanines 2010, 14, 513-533.

5. Ariga K., Hill J.P., Lee M.V., Vinu A., Charvet R., Acharya S. Sci. Technol. Adv. Mater. 2008, 9, 014109.

6. Ariga K., Hill J.P., Wakayama Y., Akada M., Barrena E., de Oteyza D.G. J. Porphyrins Phthalocyanines 2009, 13, 22-34.

7. Valkova L.A., Valli L., Casilli S., Borovkov N.Yu., Sibrina G.V., Glibin A.S., Koifman O.I., Pisani M., Rustichelli F. Langmuir 2008, 24, 4857-4864.

8. Valkova L., Borovkov N., Kopranenkov V., Pisani M., Bossi M., Rustichelli F. Mater. Sci. and Eng. C, 2002, 22, 167-170.

9. Valkova L., Borovkov N., Maccioni E., Pisani M., Rustichelli F., Erokhin V., Patternolli C., Nicolini C. Colloids Surf., A 2002, 198-200, 891-896.

10. Valkova L., Menelle A., Borovkov N., Erokhin V., Pisani M., Ciuchi F., Carsughi F., Spinozzi F., Pergolini M., Padke R., Bernstorff S., Rustichelli F. J. Appl. Crystallogr. 2003, 36, 758-762.

11. Valkova L., Borovkov N., Pisani M., Rustichelli F. Thin Solid Films 2001, 401, 267-272.

12. Cole S.J., Curthoys G.C., Magnusson E.A., Phillips J.N. Inorg. Chem. 1972, 11, 1024-1028.

13. Borovikov A.Ya., Fialkov Yu.Ya. Ukrainian Chemical Journal 1976, 42, 916-919. 
14. Hille J., Prochazka M., Feltl L., Smolkova-Keulemansova E. J. Chromatogr. 1984, 283, 77-88.

15. Sibrina G.V., Blokhina S.V., Olkhovich M.V., Borovkov N.Yu. Russ. J. Gen. Chem. 1997, 67, 472-478

16. Antina E.V. Di- and Tetrapyrrols in Solutions and Solids: Physicochemical Properties and Reactivity. Synopsis of the doctoral thesis, Ivanovo, 2006, $36 \mathrm{p}$.

17. Fu Y., Forman M., Leznoff C.C., Lever A.B.P. J. Phys. Chem. 1994, 98, 8985-8991.

18. Valkova L.A., Shabyshev L.S., Borovkov N.Yu., Feigin L.A., Rustichelli F. J. Inclusion Phenom. Macrocyclic Chem. 1999, $35,243-249$

19. Valkova L.A., Glibin A.S., Valli L. Colloid J. 2008, 70, 6-11.
20. Mikhalenko S.A., Barkanova S.V., Lebedev O.L., Luk'yanets E.A. Zh. Obshch. Khim. 1971, 41, 2735-2739 (in Russ).

21. Barrett P.A., Linstead R.P., Tuey G.A. J. Chem. Soc. 1939, 1809.

22. Volmer M.Z. Z. Phys. Chem. 1925, 115, 253-259.

23. Adam N.K. Fizika i Khimiya Poverkhnostey [Physics and Chemistry of Surfaces]. Moskva, Leningrad: Gosud. izd. tekhn. teoret. liter. 1947. $552 \mathrm{p}$.

24. Myagkov I.V., Studnev Yu.N. Kolloidn. Zh. 1985, 47, 815- 821 (in Russ.).

25. Valkova L.A., Betrencourt C., Hochapfel A., Myagkov I.V., Feigin L.A. Mol. Cryst. Liq. Cryst. 1996, 287, 269-273.

Received 26.05.2011

Accepted 30.06.2011 